\title{
Pretreatment of Agricultural Crop Wastes for Biofuels Production
}

\author{
Binling $\mathrm{Ai}^{1, \text { a }}$, Lili Zheng ${ }^{1, \mathrm{~b}}$, Xiaoyan Zheng ${ }^{1, \mathrm{c}}$ and Zhanwu Sheng ${ }^{1, \mathrm{~d}}$ \\ ${ }^{1}$ Haikou Experimental Station, Chinese Academy of Tropical Agricultural Sciences, Haikou, Hainan \\ 570102, China \\ aaibinling@163.com, ${ }^{\mathrm{b}}$ lily_0909@126.com, ${ }^{\mathrm{C}} \mathrm{zhxyhn@126.com,}{ }^{\mathrm{d}}$ shengzhanwu100@163.com
}

Keywords: pretreatment; crop straw; biofuels; cellulose; hemicellulose

Abstract. Crop straw is an abundant but still underutilized renewable resource. Most of agricultural crop wastes contain about $70 \%$ fermentable components. Pretreatment technology aims to expose the fermentable carbohydrates for hydrolytic enzymes and microbes in downstream biofuels production process. An ideal pretreatment method satisfies following criteria: greatly enhancing the enzymatic efficiency of cellulose, minimizing the loss of fermentable carbohydrates, minimizing the formation of inhibitors, and high cost effectiveness. The most studied pretreatment methods include acid pretreatment, alkaline pretreatment, steam explosion, biological pretreatment, and so on. The effects of pretreatment methods on increasing the biodigestibility include increase of surface areas, reduce of cellulose crystallinity, hemicellulose solubilization, delignification, inhibitors production. Different pretreatment method offers its advantages, and also have its own shortcomings. When selecting a pretreatment method and optimizing operation conditions, not only the characteristics of lignocellulosic feedstock but also the target product and fermentation process need to be considered.

\section{Introduction}

Crop straw is the inevitable by-product in agricultural production, and also an abundant and available renewable resource for fuels, most of which, however, is discarded without any attempt of recovery. With the increasing of resource constrain and environmental pressure, utilization of agricultural crop wastes as raw materials for biofuels production becomes a promising alternative technology. The diversity of straw components and variety of conversion methods provide possibilities to produce different kinds of biofuels [1]. Although crop straw supply is adequate and the price is low, the complexity and high cost of conversion process have limited the industrial application of this renewable resource. In the bioprocessing of lignocellulose bioconversion to fuels, the fermentable carbohydrates including cellulose and hemicellulose have to be exposed for hydrolytic enzymes and microbes [2]. Pretreatment technology has been widely studied as a key step for the efficient conversion of lignocellulosic biomass to biofuels [3, 4]. The chemical composition and structure of crop straw were summarized, and the pretreatment methods with great potential for biofuels production were reviewed and compared.

\section{Composition of agricultural crop wastes}

Cellulose, hemicellulose and lignin are the three largest components of lignocellulosic biomass [5]. Cellulose, the largest component in most of botanic body, covers 35\% 50\% of plant dry weight. Hemicellulose is the second largest component, accounting for $20 \% \sim 30 \%$ of dry weight. The content of lignin is lower than that of cellulose and hemicellulose, ranging from 5\% to $30 \%$. Cellulose and hemicellulose are the fermentable carbohydrates that can be used as substrate for converting to biofuels and bioproducts by microbes, while lignin can not be converted to biofuels by microbes. Cellulose is decomposed into glucose by hydrolytic enzymes. The hydrolysis products from hemicellulose include five-carbon monosaccharides such as xylose and arabinose, and small amount of six-carbon monosaccharides such as mannose and galactose. Table 1 presents the chemical composition of some crop straws and agricultural wastes. Corn stalk, rice straw and wheat straw are the most abundant crop straws in China. As shown in Table 1, those crop wastes contain about $70 \%$ fermentable carbohydrates. 
Table 1 The contents of cellulose, hemicellulose and lignin in agricultural crop wastes

\begin{tabular}{lllll}
\hline & Cellulose $(\%)$ & Hemicellulose $(\%)$ & Lignin $(\%)$ & Reference \\
\hline Corn stalk & $36.1 \sim 36.8$ & $29.2 \sim 30.9$ & $17.2 \sim 21.2$ & {$[6]$} \\
Rice straw & 44.3 & 24.0 & 15.6 & {$[7]$} \\
Wheat straw & $33 \sim 40$ & $20 \sim 25$ & $15 \sim 20$ & {$[8]$} \\
Sugarcane bagasse & 42 & 25 & 20 & {$[9]$} \\
Sweet sorghum & 45 & 27 & 21 & {$[9]$} \\
Corn cobs & 45 & 35 & 15 & {$[10]$} \\
Nut shells & $25 \sim 30$ & $25 \sim 30$ & $30 \sim 40$ & {$[11]$} \\
Grasses & $25 \sim 40$ & $35 \sim 50$ & $10 \sim 30$ & {$[12]$} \\
\hline
\end{tabular}

In natural plant biomass, cellulose is structurally wrapped by hemicellulose and lignin, which makes it resistant to microbial and enzymatic degradation [13, 14]. The crystal structure of cellulose also restrict the hydrolysis [15]. The physicochemical property of lignocellulosic biomass determines it more difficult to bioconversion than starchy feedstocks like corn and sucrose-containing feedstocks like sugarcane. Therefore pretreatment is an essential step in cellulose utilization.

\section{Pretreatment methods of agricultural crop wastes}

Pretreatment is employed to breakdown the combination of cellulose with hemicellulose and lignin, or/and to remove lignin to increase the specific surface area, or/and to reduce the crystallinity of cellulose [16]. An ideal pretreatment technology needs to satisfy the criteria including greatly enhancing the enzymatic efficiency of lignocellulose, minimizing the loss of fermentable carbohydrates, minimizing the formation of inhibitors of downstream enzymolysis and fermentation, and high cost effectiveness. The most common pretreatment methods are summarized in Table 2.

Table 2 Pretreatment methods of lignocellulosic feedstocks $[2,4,17]$

\begin{tabular}{ll}
\hline & Process \\
\hline Diluted acid & Milling the feedstocks into particles, adding \\
pretreatment & $\begin{array}{l}\text { diluted acid and heating to } 160 \sim 200^{\circ} \mathrm{C} \text { for } \\
\text { minutes }\end{array}$
\end{tabular}
Characteristics

Be suited to most of lignocellulosic feedstocks; Hemicellulose recovery 75\% 90\%; Reactor required high-temperature, high-pressure and corrosion resistance; Energy consumption in milling accounting for about $30 \%$ of total energy consumption; Hydrolysates required detoxification

Concentrated acid pretreatment Lower temperature and pressure with longer reaction time of $10 \sim 12 \mathrm{~h}$

Alkaline pretreatment Soaking in $\mathrm{NaOH}$ or $\mathrm{NH}_{3}$ solution

Steam explosion

Heating to $160 \sim 260^{\circ} \mathrm{C}$ with high-pressure steam; Keeping pressure at $0.69 \sim 4.83 \mathrm{MPa}$ for seconds; With a sharp release of pressure steam explosion pretreatment is accomplished

Ammonia fiber explosion
Alkaline thermal pretreatment; Exposes the lignocellulosic materials by high temperature and pressure treatment followed by rapid pressure release
Sugar recovery $90 \%$; Difficult and expensive to recover the acid

Large consumption of alkaline solution; Loss of part of hemicellulose

Hemicellulose recovery 45\% 65\%; Enzymolysis efficiency $90 \%$; Production of inhibitors like furfural; High equipment cost

Does not produce inhibitors; Small particle size is not required; Cellulose and hemicellulose conversions 90\%; Requires efficient ammonia recovery

Continued from Table 2

\begin{tabular}{|c|c|c|}
\hline & Process & Characteristics \\
\hline $\begin{array}{l}\text { Microwave } \\
\text { pretreatment }\end{array}$ & $\begin{array}{l}\text { Improve efficiency of acid and alkali } \\
\text { pretreatment; Increase reaction speed and } \\
\text { decrease reaction time }\end{array}$ & $\begin{array}{l}\text { New energy-saving technology without temperature } \\
\text { gradients; Still in the laboratory }\end{array}$ \\
\hline Biological pretreatment & $\begin{array}{l}\text { Using microorganisms like brown } \\
\text { rot, white rot and soft rot fungi to degrade } \\
\text { lignin }\end{array}$ & $\begin{array}{l}\text { Simple equipment with low running cost; Mild reaction } \\
\text { conditions with less inhibitors; Low treatment } \\
\text { efficiency with long processing period of weeks; white } \\
\text { and soft rots attack both cellulose and lignin }\end{array}$ \\
\hline
\end{tabular}




\section{Comparison of pretreatment methods for biofuels production}

The biodegradability of lignocellulosic feedstocks is affected by accessible surface areas, lignin content and cellulose crystallinity. In addition, the amount of inhibitors produced in pretreatment process greatly influences the feedstocks utilization in downstream processes [18]. The effects of different pretreatment methods on improving the biodegradability of lignocellulosic feedstocks include chemical composition and structures and inhibitors production (Table 3).

Table 3 Effects of pretreatment methods on lignocellulosic feedstocks (adapted from [17])

\begin{tabular}{lllllll}
\hline & $\begin{array}{l}\text { Increase of } \\
\text { surface } \\
\text { areas }\end{array}$ & $\begin{array}{l}\text { Reduce of } \\
\text { cellulose } \\
\text { crystallinity }\end{array}$ & $\begin{array}{l}\text { Hemicellulose } \\
\text { hydrolyzation }\end{array}$ & Delignification & $\begin{array}{l}\text { Changes } \\
\text { in lignin } \\
\text { structure }\end{array}$ & $\begin{array}{l}\text { Inhibitors } \\
\text { production }\end{array}$ \\
\hline Mechanical & $+{ }^{\mathrm{a}}$ & + & & & & \\
Steam explosion & + & & + & - & + & + \\
$\mathrm{CO}_{2}$ explosion & + & & + & & & \\
Liquid hot water & + & 0 & + & $+/-$ & - & - \\
Acid pretreatment & + & & + & - & + & + \\
Alkaline pretreatment & + & & - & $+/-$ & + & - \\
Ammonia pretreatment & + & + & - & + & + & - \\
Wet oxidation & + & 0 & & $+/-$ & + & - \\
\hline
\end{tabular}

${ }^{\mathrm{a}}+$, Major effect; -, Minor effect; ○, Not determined.

All those pretreatment methods offer their advantages, and also have their own shortcomings. The pretreatment performance depends on the chemical composition and structure of lignocellulosic feedstocks and the pretreatment operation. Specific pretreatment methods and operation conditions need to be selected and optimized for certain types of lignocellulosic feedstocks. Another factor of assess and selection of pretreatment methods is the target product. Compared to ethanol fermentation, methane production process has high resistance to furfural and hydroxymethylfurfural the inhibitors produced in pretreatment process. So when selecting pretreatment method for methane fermentation, inhibitors production is not considered as much as for ethanol fermentation.

\section{Conclusions}

Crop straw is an abundant and available renewable lignocellulosic resource for biofuels production. Most of crop wastes contain about $70 \%$ fermentable carbohydrates. Pretreatment technology is a key step for increasing the biodigestibility of cellulose in lignocellulosic feedstocks. The major effects of pretreatment technology include increase of surface areas, reduce of cellulose crystallinity, hemicellulose hydrolyzation, delignification, inhibitors production. According to the target product and fermentation process, specific pretreatment method and operation condition need to be selected and optimized for certain type of lignocellulosic feedstocks.

\section{Acknowledgements}

This work was financially supported by the National Natural Science Foundation of China (Grant No. 51708548) and the Central Public-interest Scientific Institution Basal Research Fund for Chinese Academy of Tropical Agricultural Sciences (Grant No. 17CXTD-05, 1630092017005).

\section{References}

[1] C. L. Williams, T. L. Westover, R. M. Emerson, J. S. Tumuluru and C. Li: BioEnerg. Res. Vol. 9 (2016), p. 1-14

[2] R. Ravindran and A. K. Jaiswal: Bioresour. Technol. Vol. 199 (2016), p. 92-102

[3] S. Haghighi Mood, A. Hossein Golfeshan, M. Tabatabaei, G. Salehi Jouzani, G. H. Najafi, M. Gholami and M. Ardjmand: Renew. Sustain. Energ. Rev. Vol. 27 (2013), p. 77-93 
[4] S. Behera, R. Arora, N. Nandhagopal and S. Kumar: Renew. Sustain. Energ. Rev. Vol. 36 (2014), p. $91-106$

[5] G. Guerriero, J.-F. Hausman, J. Strauss, H. Ertan and K. S. Siddiqui: Eng. Life Sci. Vol. 16 (2016), p. 1-16

[6] K. Öhgren, R. Bura, J. Saddler and G. Zacchi: Bioresour. Technol. Vol. 98 (2007), p. 2503-2510

[7] S. Zhu, Y. Wu, Z. Yu, C. Wang, F. Yu, S. Jin, Y. Ding, R. a. Chi, J. Liao and Y. Zhang: Biosys. Eng. Vol. 93 (2006), p. 279-283

[8] P. McKendry: Bioresour. Technol. Vol. 83 (2002), p. 37-46

[9] M. Kim and Day D. F: J. Ind. Microbiol. Biotechnol. Vol. 38 (2011), p. 803-807

[10] S. Prasad, A. Singh and H. C. Joshi: Resour., Conserv. Recy. Vol. 50 (2007), p. 1-39

[11]Z. Anwar, M. Gulfraz and M. Irshad: J. Radiat. Res. Appl. Sci. Vol. 7 (2014), p. 163-173

[12] S. Malherbe and T. E. Cloete: Rev. Env. Sci. Biotech. Vol. 1 (2002), p. 105-114

[13] Y. Su, R. Du, H. Guo, M. Cao, Q. Wu, R. Su, W. Qi and Z. He: Food Bioprod. Process. Vol. 94 (2015), p. 322-330

[14] Y. Zeng, S. Zhao, S. Yang and S.-Y. Ding: Curr. Opin. Biotechnol. Vol. 27 (2014), p. 38-45

[15]Peciulyte, K. Karlström, P. T. Larsson and L. Olsson: Biotechnol. Biofuels Vol. 8 (2015), p. 56

[16] S. Sun, S. Sun, X. Cao and R. Sun: Bioresour. Technol. Vol. 199 (2016), p. 49-58

[17]A. Hendriks and G. Zeeman: Bioresour. Technol. Vol. 100 (2009), p. 10-18

[18]L. J. Jönsson and C. Martín: Bioresour. Technol. Vol. 199 (2016), p. 103-112 